\title{
The Effectiveness of Interpersonal Psychotherapy Versus Cognitive Behavioral Therapy for Eating Disorders: A Systematic Review and Meta-analysis
}

\section{Qihang Xie}

Anhui Medical College: Anhui Medical University

\section{Pengcheng Yi}

Zhejiang Provincial People's Hospital

\section{Xinyang $\mathrm{Hu}$}

Anhui Medical College: Anhui Medical University

Jianxiang Lei

Anhui Medical College: Anhui Medical University

Jiacheng Kong

Anhui Medical College: Anhui Medical University

\section{Yang Zhang}

Fourth People's Hospital of Hefei

\section{Meng Liang}

Chaohu Hospital of Anhui Medical University

Jingyi Luo

Chaohu Hospital of Anhui Medical University

Xiaoming Li ( $\square$ psyxiaoming@126.com )

Anhui Medical University https://orcid.org/0000-0002-5228-1372

\section{Research Article}

Keywords: Eating disorder, Interpersonal psychotherapy, Cognitive behavioral therapy, Review, Meta-analysis

Posted Date: September 3rd, 2021

DOI: https://doi.org/10.21203/rs.3.rs-867140/v1

License: (a) (i) This work is licensed under a Creative Commons Attribution 4.0 International License. Read Full License 


\section{Abstract}

Purpose: Interpersonal psychotherapy (IPT) has been proposed as a treatment strategy for eating disorders (EDs). However, cognitive behavioral therapy (CBT) is the treatment more effectively and widely used than IPT. We conducted a systematic review and meta-analysis of randomized controlled trials (RCTs) to compare the effectiveness of IPT versus CBT on EDs.

Methods: We systematically searched PubMed, Embase, Medline, Cochrane, Web of Science, and the Clinical Trials Database for RCTs that compared IPT and CBT.

Results: Of 468 studies initially identified, 10 were suitable for incorporation into our meta-analysis $(\mathrm{N}=833$ participants). In those studies, IPT and CBT had comparable effects in terms of primary outcome (i.e., ED score) $(S M D=0.08)$, while IPT had a better effect in terms of secondary outcome (i.e., Inventory of Interpersonal Problems) $(S M D=0.32)$ than $C B T$. Compared with $C B T$, IPT had a better treatment effect for ED populations with lower Body Mass Index $(S M D=0.27)$ and age $(S M D=0.43)$. IPT and CBT both had follow-up effects of pre-test and follow-up comparison after fewer than 6 months (SMD $=1.61,1.83), 6-12$ months (SMD $=1.48,1.65)$, and more than 12 months $(S M D=1.29,1.33)$. At the same time, only $C B T$ showed a dose-response relationship trend $(\beta=0.017, p=0.067)$.

Conclusion: The meta-analysis provided clear evidence that IPT is an effective treatment measure for patients with EDs. This review also suggested that future research is needed to determine the effects of IPT in the treatment of EDs.

Level of evidence Level I, systematic review and meta-analysis.

\section{What Is Already Known On This Subject?}

Eating disorders (EDs) are a group of diseases characterized by abnormal eating habits and excessive attention to food, weight and body shape. The treatment of EDs mainly includes two psychotherapies: one is cognitive behavioral therapy (CBT), another one is Interpersonal psychotherapy (IPT). In view of literatures, a series of clinical trials have assessed IPT against CBT, but single study might not be able to compare the difference of the efficiency between IPT and CBT because of the small sample size in these studies. Moreover, only a few systematic reviews examined the effects of IPT on other disorders. However, no meta-analysis has focused on IPT for EDs.

\section{What Does This Study Add?}

The present study is the first meta-analysis to compare the effects of CBT and IPT in terms of their use as treatment for EDs. The results showed that, compared with CBT, IPT had a visible effect in terms of changing the score on the EDE scale. These data support IPT as a treatment strategy that can reduce ED symptoms. Moreover, compared with CBT, IPT has better treatment effect on Ed population with smaller $\mathrm{BMI}$ or age. These have important significance for the diversification of treatment methods and the choice of applicable populations. 


\section{Compliance with Ethical Standards}

\section{Introduction}

Eating disorders (EDs) are a group of diseases characterized by abnormal eating habits and excessive attention to food, weight, and body shape [37]. These diseases include anorexia nervosa (AN), bulimia nervosa (BN), binge eating disorder (BED), and other EDs that are connected with meaningful physical and psychological distress [4]. AN is a type of ED characterized by the inability to maintain a normal healthy body weight, often falling below $85 \%$ of ideal body weight. BN is characterized by recurrent episodes of binge eating in combination with some form of inappropriate compensatory behavior, like fasting, excessive exercise etc [8].

Abnormal behavior in EDs occurs no less often than in any other physical or mental illness. In most patients, fear of and attempts to counteract the effects of gaining weight are the most typical psychopathology that emerges. Underage girls and young women, who are typically white and live in western nations, are most often affected by EDs. It is estimated that $3 \%$ of young women suffer from EDs $(0.7 \% \mathrm{AN}, 1-2 \% \mathrm{BN})$, and the incidence of EDs is rising [14].

Cognitive behavioral therapy (CBT) is widely used as the gold-standard treatment for EDs and has been practiced as a treatment for EDs for decades [23]. Over time, it no longer causes anxiety or fear [17]. Interpersonal psychotherapy (IPT), on the other hand, is a new treatment both in the use of exposure therapy and long-term effectiveness [30, 32].

Klerman and colleagues introduced IPT in the 1970s while studying the acute phase of treatment for major depression [29]. IPT is a time-limited, affect-, life event-, and present-focused psychotherapy that emphasizes the interpersonal context of symptoms [28]. It has been demonstrated to successfully treat depressive disorder and helped patients develop healthy social relationships [2].

Current treatment for BN includes two main therapies: $\mathrm{CBT}$, which begins with addressing the patient's deviant self-perception and excessive obsession with weight control and then focuses on the problem by conducting multi-angle interventions from cognition to behavior. Scientific research and clinical practice have demonstrated that this therapy is effective [20]. On the other hand, IPT is also of great significance for the healthy development of adolescents.

Early acceptance of effective psychotherapy is conducive to the personal development of adolescents. CBT places great emphasis on consciousness and, once the patient's consciousness is weakened, CBT cannot continue, because the most important element of $\mathrm{CBT}$ is that the patient and social worker complete the construction of the so-called the Antecedents, Behavior, Consequences model. This model is one of the most prominent $\mathrm{CBT}$ techniques for analysing thoughts, behavior, and emotions [26]. It involves the patient and social worker filling in the ED scale together, which should be completed according to the patient's selfawareness. 
Unlike other psychotherapy techniques, however, IPT does not emphasize etiology or causation, such as assuming that unfortunate social events cause depression. Instead, it allows patients to learn to associate emotions with interpersonal interactions and alleviate depression through appropriate interpersonal adjustment and relationship improvement [36]. In clinical practice, IPT is used less often than CBT, which would appear to mean that CBT is the more effective treatment ED. However, no immediate or long-term difference is evident in the results of IPT and CBT in the treatment of EDs, and studies have pointed out that $46.5 \%$ of patients are inclined to CBT, while $53.5 \%$ are inclined to IPT. Studies have also demonstrated that CBT has a higher drop-out rate than IPT [38]. The effectiveness of CBT versus IPT, however, is not reflected in these studies. The relationship between IPT and CBT in the treatment of EDs has not been covered in the literature, and no research has examined the comparative treatment effects of the two techniques [10]. Therefore, this study sought to examine and compare the treatment effects of IPT and CBT for EDs.

A series of clinical trials has assessed IPT compared to CBT [6,27]. However, a single study's ability to determine the differences in effectiveness of IPT and CBT may be limited by small sample size. Moreover, only a few systematic reviews have examined the overall effects of IPT. Some have focused on the effects of IPT for depression [11], while others have focused on narrow research topics, such as the comparison between IPT and normal care [21]. No meta-analysis has focused on IPT for EDs. We therefore conducted a systematic review and meta-analysis of randomized controlled trials (RCTs) to provide evidence regarding whether IPT or CBT is more effective in the treatment of EDs from the same experimental comparisons.

\section{Methods}

This systematic review and meta-analysis is reported in accordance with the Preferred Reporting Items for Systematic Reviews and Meta-Analysis (PRISMA) statement and was registered at International Prospective Register of Systematic Reviews (CRD42020173888).

\section{Study selection and data extraction}

Our inclusion criteria consisted of RCTs on ED, BED, AN, or BN, comparison of IPT with CBT, examination of the effects of exposure, and reported changes at long-term follow-up. The identified studies included multiple scales to evaluate the effects of the interventions. Our inclusion criteria had no requirements for the diagnosis, size, or group characteristics of the samples. Only articles written in English were included. Research that took the forms of protocol study or case report, that had incomplete data, or that did not assess IPT as a treatment for EDs was excluded.

We selected studies by searching PubMed, Web of Science, Medline, the Clinical Trials Database, Cochrane, and Embase to from inception through May 30, 2021. We used the combined text and MeSH terms of "eating disorder" and "interpersonal psychotherapy." The complete search used for PubMed was: (Search (((((“Feeding and Eating Disorders”[MeSH] )) OR (((()((((Feeding Disorders[Title/Abstract]) OR Disorder, Feeding[Title/Abstract]) OR Disorders, Feeding[Title/Abstract]) OR Feeding Disorder[Title/Abstract]) OR Eating Disorders[Title/Abstract]) OR Disorder, Eating[Title/Abstract]) OR Disorders, Eating[Title/Abstract]) OR Eating Disorder[Title/Abstract]) OR Appetite Disorders[Title/Abstract]) OR Appetite 
Disorder[Title/Abstract]))) AND ((Psychotherapy, Interpersonal[Title/Abstract]) OR "Interpersonal Psychotherapy"[MeSH])) AND ((Randomized controlled trial [Publication Type] OR randomized [Title/Abstract] OR placebo [Title/Abstract]))). To identify other potentially similar studies, we reviewed a series of related studies and reviews and also checked unpublished studies.

Two independent researchers (Q.X. and X.H.) browsed the titles and abstracts of the articles as well as the full texts of the articles that met the inclusion criteria. The collection and analysis of experimental data was done by two researchers (Q.X. and X.H.) and required $96 \%$ agreement. In the case of differing opinions, the third researcher (J.L.) would be called upon to resolve the issue.

We extracted the following data from each qualified article: number of participants, gender, age, IPT or CBT treatment, trial duration, and change in scale score. Two independent reviewers (Q.X. and J.L.) assessed the risk for bias according to the PRISMA recommendations.

\section{Statistical analysis}

As a primary outcome, we analyzed the Eating Disorder Examination (EDE) scale score as continuous variables and reported the differences between the standardized means before and after the interventions. In addition, we conducted follow-up effect analysis assessed by the same outcome. EDE is an investigational method used to determine the psychopathological characteristics of EDs. According to the investigation method of the DSM-囚, it is adjusted to diagnose EDs as well as to identify psychopathological changes in disordered [15]. We also used the Inventory of Interpersonal Problems (IIP) as a secondary outcome, which identifies abnormal interpersonal communication patterns and can reflect the severity of EDs.

Next, we calculated the standardized mean difference (SMD) in the EDE scores by using a random-effects model (the inverse variance method). Moreover, to fully explain the additional uncertainties associated with the differences between the studies of the effects of IPT and CBT, in the meta-analysis of each result, we performed a pre-planned sensitivity analysis of trials comparing IPT and CBT. This comparison is the most important clinical question related to the effectiveness of IPT. In the overall analysis, the heterogeneity of the result changes caused by treatment in the control group was also reduced.

Finally, we assessed the likelihood of publication bias by constructing a funnel plot of the effect size and standard error of each trial. The Cochrane $\mathrm{Q}$ test was used to assess the heterogeneity of the studies, and we also performed an $1^{2}$ test to assess the degree of heterogeneity between studies. If the value was greater than $50 \%$, the heterogeneity was considered moderate to high. All statistical analyses were conducted using Review Management (version 5.3) and Stata version 15.0.

\section{Results}

\section{Characteristics of the included studies}


We initially identified 468 studies, of which 10 ( $n=833$ participants) were ultimately included in our analysis (Fig. 1). A total of 174 duplicate articles were removed from the initial 468 studies. By reading the abstract and title, we removed an additional 272 case reports, protocols, pilot studies, reviews, and articles in which the disease under discussion was not an ED or in which the treatment was not IPT. After reading the full text of the qualified articles, we discarded a further 12 because their treatment method was not IPT or the disease under study was not an ED.

The 10 trials that we reviewed in full were all RCTs that directly compared CBT with IPT in the same experiment (Table 1). The mean trial duration was 18 weeks. The mean age of the participants ranged from 24.2 to 50.3 years. Sample types included BED $[1,34,38,40]$, AN $[7,31]$, and BN $[9,15,13]$. Eight trials included a follow-up and compared IPT with CBT $[1,13,15,19,31,34,38,40]$. The follow-up time spans more than 12 months. Two trials compared IPT with CBT and had no specific control management [7, 31]. One trial compared IPT with CBT and behavioral weight loss treatment [40]. 
Table 1

Studies included in the Meta-analysis and their Characteristics

\begin{tabular}{|c|c|c|c|c|c|c|c|}
\hline Study & $\begin{array}{l}\text { Sample } \\
\text { type }\end{array}$ & $\begin{array}{l}\text { Study } \\
\text { design }\end{array}$ & $\begin{array}{l}\mathbf{N} \\
\text { (each } \\
\text { group) }\end{array}$ & $\begin{array}{l}\text { Age } \\
\text { (years,mean) }\end{array}$ & Design & $\begin{array}{l}\text { Other } \\
\text { intervention } \\
\text { aspects }\end{array}$ & $\begin{array}{l}\text { Outcome } \\
\text { measure }\end{array}$ \\
\hline \multirow{5}{*}{$\begin{array}{l}\text { Agras, } \\
1995\end{array}$} & \multirow{5}{*}{$\begin{array}{l}\text { Binge } \\
\text { eating } \\
\text { disorder } \\
\text { (BED) }\end{array}$} & \multirow[t]{5}{*}{$\mathrm{RCT}$} & \multirow[t]{5}{*}{31,11} & \multirow[t]{5}{*}{47.6} & \multirow{2}{*}{$\begin{array}{l}24 \\
\text { weeks } \\
\text { of IPT }\end{array}$} & \multirow{5}{*}{$\begin{array}{l}\text { Assessments } \\
\text { occurred at pre- } \\
\text { treatment, } 12 \\
\text { and } 24 \text { weeks } \\
\text { follow-up }\end{array}$} & EDE \\
\hline & & & & & & & BES \\
\hline & & & & & \multirow{3}{*}{$\begin{array}{l}\text { Vs. } \\
\text { CBT }\end{array}$} & & IIP \\
\hline & & & & & & & SCL-90 \\
\hline & & & & & & & $\mathrm{BDI}$ \\
\hline \multirow[t]{2}{*}{$\begin{array}{l}\text { Carter, } \\
2010\end{array}$} & \multirow[t]{2}{*}{$\begin{array}{l}\text { Anorexia } \\
\text { Nervosa }\end{array}$} & \multirow[t]{2}{*}{ RCT } & \multirow[t]{2}{*}{$14,17 \rrbracket 12$} & \multirow[t]{2}{*}{ NA } & $\begin{array}{l}\text { at least } \\
20 \\
\text { weeks } \\
\text { of IPT } \\
\text { vs. }\end{array}$ & \multirow[t]{2}{*}{$\begin{array}{l}\text { Assessments } \\
\text { occurred at pre- } \\
\text { treatment and } \\
\text { post-treatment }\end{array}$} & $\begin{array}{l}\text { global } \\
\text { anorexia } \\
\text { nervosa } \\
\text { measure }\end{array}$ \\
\hline & & & & & $\begin{array}{l}\text { CBT vs } \\
\text { NSCM }\end{array}$ & & \\
\hline \multirow{6}{*}{$\begin{array}{l}\text { Chui, } \\
2007\end{array}$} & \multirow{6}{*}{$\begin{array}{l}\text { Bulimia } \\
\text { Nervosa }\end{array}$} & \multirow[t]{6}{*}{ RCT } & \multirow[t]{6}{*}{59,65} & \multirow[t]{6}{*}{28.61} & $\begin{array}{l}\text { at least } \\
20\end{array}$ & \multirow{6}{*}{$\begin{array}{l}\text { Assessments } \\
\text { occurred at pre- } \\
\text { treatment, post- } \\
\text { treatment and } \\
12 \text { weeks } \\
\text { follow-up }\end{array}$} & \\
\hline & & & & & $\begin{array}{l}\text { weeks } \\
\text { of IPT }\end{array}$ & & EDE \\
\hline & & & & & vs. & & SCID \\
\hline & & & & & \multirow[t]{3}{*}{$\mathrm{CBT}$} & & SCL-90 \\
\hline & & & & & & & IIP \\
\hline & & & & & & & RSS \\
\hline \multirow{3}{*}{$\begin{array}{l}\text { Fairburn, } \\
1993\end{array}$} & Bulimia & \multirow[t]{3}{*}{ RCT } & \multirow[t]{3}{*}{25,25} & \multirow[t]{3}{*}{24.2} & \multirow{2}{*}{$\begin{array}{l}\text { at least } \\
18 \\
\text { weeks } \\
\text { of IPT } \\
\text { vs. }\end{array}$} & \multirow{3}{*}{$\begin{array}{l}\text { Assessments } \\
\text { occurred at } \\
\text { pre-treatment, } \\
\text { post- } \\
\text { treatment, } 4,8 \text {, } \\
\text { and } 12 \text { months } \\
\text { follow-up }\end{array}$} & EDE \\
\hline & Nervosa & & & & & & EAT \\
\hline & & & & & $\mathrm{CBT}$ & & \\
\hline
\end{tabular}

Abbreviation: IPT interpersonal phychotherapy, CBT: cognitive behavioral therapy, BES: Binge Eating Scale, BDI: Beck Depression Inventory, IIP: Inventory of Interpersonal Problems, SCL-90: Symptom Check List - 90, BMI: Body Mass Index, RSS: Rosenberg Self-esteem Scale, EAT: Eating Attitude Test, EDE-Q: Eating Disorder Examination Questionnaire, BSI: Brief Symptom Inventory, GAF: Global Assessment of Functioning 


\begin{tabular}{|c|c|c|c|c|c|c|c|}
\hline Study & $\begin{array}{l}\text { Sample } \\
\text { type }\end{array}$ & $\begin{array}{l}\text { Study } \\
\text { design }\end{array}$ & $\begin{array}{l}\mathbf{N} \\
\text { (each } \\
\text { group) }\end{array}$ & $\begin{array}{l}\text { Age } \\
\text { (years,mean) }\end{array}$ & Design & $\begin{array}{l}\text { Other } \\
\text { intervention } \\
\text { aspects }\end{array}$ & $\begin{array}{l}\text { Outcome } \\
\text { measure }\end{array}$ \\
\hline $\begin{array}{l}\text { Fairbunr, } \\
2015\end{array}$ & $\begin{array}{l}\text { Bulimia } \\
\text { Nervosa }\end{array}$ & RCT & 65,65 & $\begin{array}{l}26.8 \\
24.9\end{array}$ & $\begin{array}{l}\text { at least } \\
20 \\
\text { weeks } \\
\text { of IPT } \\
\text { vs. } \\
\text { CBT }\end{array}$ & $\begin{array}{l}\text { Assessments } \\
\text { occurred at } \\
\text { pre-treatment, } \\
\text { post- } \\
\text { treatment,20,40 } \\
\text { and } 60 \text { weeks } \\
\text { follow-up }\end{array}$ & EDE \\
\hline $\begin{array}{l}\text { Hilbert, } \\
2012\end{array}$ & $\begin{array}{l}\text { Binge } \\
\text { eating } \\
\text { disorder } \\
\text { (BED) }\end{array}$ & RCT & 45,45 & $\begin{array}{l}44.02 \\
45.73\end{array}$ & $\begin{array}{l}\text { at least } \\
20 \\
\text { weeks } \\
\text { of IPT } \\
\text { vs. } \\
\text { CBT }\end{array}$ & $\begin{array}{l}\text { Assessments } \\
\text { occurred at pre- } \\
\text { treatment, post- } \\
\text { treatment, 1- } \\
\text { year follow-up } \\
\text { and long-term } \\
\text { follow-up }\end{array}$ & $\begin{array}{l}\text { EDE } \\
\text { EDE-Q } \\
\text { BSI } \\
\text { BMI }\end{array}$ \\
\hline $\begin{array}{l}\text { Mcintosh, } \\
2005\end{array}$ & $\begin{array}{l}\text { Anorexia } \\
\text { Nervosa }\end{array}$ & RCT & $\begin{array}{l}21,19 \\
16\end{array}$ & NA & $\begin{array}{l}\text { at least } \\
20 \\
\text { weeks } \\
\text { of IPT } \\
\text { vs. } \\
\text { CBT vs } \\
\text { NSCM }\end{array}$ & $\begin{array}{l}\text { Assessments } \\
\text { occurred at pre- } \\
\text { treatment. } \\
\text { post-treatment }\end{array}$ & $\begin{array}{l}\text { GAF } \\
\text { DSM-IV } \\
\text { EDE }\end{array}$ \\
\hline $\begin{array}{l}\text { Tasca, } \\
2012\end{array}$ & $\begin{array}{l}\text { Binge } \\
\text { eating } \\
\text { disorder } \\
\text { (BED) }\end{array}$ & RCT & 48,47 & 32.7 & $\begin{array}{l}16 \\
\text { weeks } \\
\text { of GPIP } \\
\text { Vs. } \\
\text { GCBT }\end{array}$ & $\begin{array}{l}\text { Assessments } \\
\text { occurred at } \\
\text { Pre-treatment, } \\
\text { Post-treatment } \\
\text { and six month } \\
\text { follow-up }\end{array}$ & $\begin{array}{l}\text { IIP } \\
\text { EDE } \\
\text { TRIPED }\end{array}$ \\
\hline $\begin{array}{l}\text { Wlifley, } \\
2002\end{array}$ & $\begin{array}{l}\text { Binge } \\
\text { eating } \\
\text { disorder } \\
\text { (BED }\end{array}$ & RCT & 81,81 & $\begin{array}{l}25.7 \\
24.7\end{array}$ & $\begin{array}{l}20 \\
\text { weeks } \\
\text { of IPT } \\
\text { Vs. } \\
\text { CBT }\end{array}$ & $\begin{array}{l}\text { Assessments } \\
\text { occurred at } \\
\text { Pre-treatment, } \\
\text { Post-treatment } \\
, 4,8 \text { and } 12 \\
\text { month follow- } \\
\text { up }\end{array}$ & $\begin{array}{l}\text { EDE } \\
\text { IIP } \\
\text { BMI } \\
\text { DSM-囚-R }\end{array}$ \\
\hline
\end{tabular}

Abbreviation: IPT interpersonal phychotherapy, CBT: cognitive behavioral therapy, BES: Binge Eating Scale, BDI: Beck Depression Inventory, IIP: Inventory of Interpersonal Problems, SCL-90: Symptom Check List - 90, BMI: Body Mass Index, RSS: Rosenberg Self-esteem Scale, EAT: Eating Attitude Test, EDE-Q: Eating Disorder Examination Questionnaire, BSI: Brief Symptom Inventory, GAF: Global Assessment of Functioning 


\begin{tabular}{|c|c|c|c|c|c|c|c|}
\hline Study & $\begin{array}{l}\text { Sample } \\
\text { type }\end{array}$ & $\begin{array}{l}\text { Study } \\
\text { design }\end{array}$ & $\begin{array}{l}\mathbf{N} \\
\text { (each } \\
\text { group) }\end{array}$ & $\begin{array}{l}\text { Age } \\
\text { (years,mean) }\end{array}$ & Design & $\begin{array}{l}\text { Other } \\
\text { intervention } \\
\text { aspects }\end{array}$ & $\begin{array}{l}\text { Outcome } \\
\text { measure }\end{array}$ \\
\hline $\begin{array}{l}\text { Wilson, } \\
2010\end{array}$ & $\begin{array}{l}\text { Binge } \\
\text { eating } \\
\text { disorder } \\
\text { (BED) }\end{array}$ & $\mathrm{RCT}$ & $\begin{array}{l}75,64 \\
66\end{array}$ & $\begin{array}{l}48.7 \\
46.2 \\
50.3\end{array}$ & $\begin{array}{l}24 \\
\text { weeks } \\
\text { of IPT } \\
\text { Vs. } \\
\text { BWL } \\
\text { Vs. } \\
\text { CBTgsh }\end{array}$ & $\begin{array}{l}\text { Assessments } \\
\text { occurred at } \\
\text { Pre-treatment, } \\
\text { Post-treatment } \\
11 \text { and } 2 \text { year } \\
\text { follow-up }\end{array}$ & $\begin{array}{l}\text { EDE } \\
\text { DSM-IV }\end{array}$ \\
\hline $\begin{array}{l}\text { Abbrevic } \\
\text { Scale, B } \\
\text { List }-9 \\
\text { Eating D } \\
\text { Functior }\end{array}$ & $\begin{array}{l}\text { PTainte } \\
\text { k Depre } \\
\text { Body N } \\
\text { r Exami }\end{array}$ & $\begin{array}{l}\text { sonal p } \\
\text { on Inver } \\
\text { s Index, } \\
\text { ion Que }\end{array}$ & $\begin{array}{l}\text { hother } \\
\text { y, IIP: II } \\
\text { S: Rose } \\
\text { onnaire }\end{array}$ & $\begin{array}{l}\text { BT: cognitive } \\
\text { ory of Interper } \\
\text { g Self-esteem } \\
\text { Brief Symptol }\end{array}$ & $\begin{array}{l}\text { ehavioral } \\
\text { onal Prob } \\
\text { cale, EAT: } \\
\text { Inventory }\end{array}$ & $\begin{array}{l}\text { רerapy, BES: Bing } \\
\text { ms, SCL-90: Sym } \\
\text { Eating Attitude Te } \\
\text { GAF: Global Asse }\end{array}$ & $\begin{array}{l}\text { Eating } \\
\text { om Check } \\
\text {, EDE-Q: } \\
\text { ment of }\end{array}$ \\
\hline
\end{tabular}

\section{Quality assessment and publication bias}

The Cochrane Risk of Bias assessment is shown in Fig. 2A, which shows that the common risk factor for bias was random sequence generation. Five of the ten studies did not use random sequences entirely, which could have resulted in the participants not being randomized. Fig. 2B shows the risk of bias: seven of the ten studies did not clearly describe the allocation method. However, all of the trials used blinding and had a low risk of bias.

\section{Primary outcome analysis}

Fig. 3A shows the effects of IPT compared to CBT in the treatment of EDs. The meta-analysis revealed similar effects compared to $\mathrm{CBT}$ in reducing EDE scores. Pooling the data of all these studies showed that IPT led to a mean reduction in scale score that was close to or slightly better than CBT (10 studies, $n=833$, $\mathrm{SMD}=0.08,95 \% \mathrm{Cl}:-0.07$ to $0.22, \mathrm{p}=0.29)$, and we detected no publication bias $(\mathrm{p}=0.29$, Fig. $3 \mathrm{~A})$. The heterogeneity of the literature data was low $\left(p=0.37,1^{2}=7 \%\right)$. The funnel plot, as shown in Fig. 3B, identified no outlier studies. Egger's test showed no published offset $(p=0.932)$.

\section{Follow-up effect analysis of IPT versus CBT}

To analyze the follow-up effects (Fig. 4), we conducted statistical analysis on the basis of dividing the follow-up periods into three time frames (less than 6 months, 6-12 months, and more than 12 months). The three time frames of pre-test and follow-up comparison all showed follow-up effects in fewer than six months (CBT: SMD = 1.83, 95\% Cl: 0.28-3.39; IPT: SMD = 1.61, 95\% Cl: 0.38-2.85), 6-12 months (CBT: SMD $=1.65,95 \%$ Cl: $0.82-2.48 ;$ IPT: SMD $=1.48,95 \%$ Cl: $0.79-2.18)$ and more than 12 months (CBT: SMD $=1.33,95 \% \mathrm{Cl}: 1.00-1.66$; IPT: SMD $=1.29,95 \%$ Cl: 1.06-1.51). However, no differences in terms of followup effects between IPT and CBT were identified.

\section{Secondary outcome analysis}


As a secondary outcome, we analyzed the IIP to provide additional evidence regarding the effects of IPT and CBT. Five studies $(n=574)$ were incorporated into the analysis. Fig. 5 illustrates that this analysis showed IPT to be slightly superior than CBT (SMD $\left.=0.32,95 \% \mathrm{Cl}: 0.07-0.56, \mathrm{p}=0.01, \mathrm{I}^{2}=38\right)$.

\section{Subgroup analysis}

To perform subgroup analysis, first, we compared the therapeutic effects of IPT and CBT between two patient types: patients with $\mathrm{AN}$ and patients with $\mathrm{BN}$ (Fig. 6A). The results showed that the two treatments were equivalent in terms of their therapeutic effect (AN: $S M D=0.16,95 \% \mathrm{Cl}:-0.31-0.62 ; \mathrm{BN}$ : $\mathrm{SMD}=0.07$, $95 \% \mathrm{Cl}:-0.10-0.24)$. An additional subgroup analysis examined whether age made any difference to treatment effect (Fig. 6B). For people older than 40, the two treatments had the same therapeutic effect $(S M D=0.17,95 \mathrm{Cl} \%:-0.07-0.42, p=0.17)$, while for people younger than 40 , IPT had a greater effect size $(\mathrm{SMD}=0.43,95 \% \mathrm{Cl}: 0.25-0.61, \mathrm{p}<0.001)$.

In the BMI subgroup analysis (Fig. 6C), we found that people with a BMI of less than 30 had a larger effect size when comparing IPT to CBT (SMD $=0.27,95 \% \mathrm{Cl}: 0.06-0.48, p=0.01$ ) as opposed to people with a $\mathrm{BMI}$ higher than 30 (SMD $=-0.34,95 \% \mathrm{Cl}:-0.83-0.15, \mathrm{p}=0.17)$. Moreover, there were significant differences between the subgroups $(p=0.03)$.

\section{Meta-regression analysis of treatment sessions}

The meta-regression analysis showed that CBT had a trend of dose-response relationship $(\beta=0.017, p=$ 0.067 , Fig. $7 \mathrm{~A}$ ), suggesting that the more sessions a patient underwent, the better the effect. IPT, on the other hand, showed no dose-response relationship $(\beta=0.003, p=0.495$, Fig. 7B).

\section{Discussion}

To the best of our knowledge, the present study is the first meta-analysis to compare the effects of CBT and IPT in terms of their use as treatment for EDs. The effect sizes of CBT and IPT can be compared directly because the data came from the same experimental comparisons. The results showed that, compared with CBT, IPT had a visible effect in terms of changing the score on the EDE scale. These data support IPT as a treatment strategy that can reduce ED symptoms.

The primary outcome also demonstrated that IPT and CBT have comparable effectiveness, which indicates that IPT could be a viable choice for treating EDs. At the same time, a previous studies found that interpersonal problems play an essential role in adults with EDs [3], which would appear to support the use of both IPT and CBT to treat EDs. However, ED patients undergoing IPT treatment often experience stress and mood difficulties, which can be reduced by involving family or friends in treatment. Thus, in the future, family-based IPT may become a preferred treatment for EDs [25]. However, compared to pre-adolescents without EDs, pre-adolescents with EDs have little healthy family communication [12], which is likely related to the child's ED and may also be an early cause of EDs. As such, it is very important for families to participate in the weight management of adolescents [39]. 
Both the primary and secondary outcomes suggested that the effect of IPT on ED treatment was comparable to that of CBT. Furthermore, based on the IIP, it appeared that IPT may have resulted in a better score and improved effect due to the interpersonal problems that can affect a patient's motivation to attend therapy [2]. As patients with EDs often have interpersonal problems, IPT can assist in symptom reduction by enhancing social functioning, repairing and constructing supports, improving communication, and resolving interpersonal conflicts. In this way, IPT is better equipped to improve interpersonal problems than $\mathrm{CBT}$, which is also reflected in the treatment effect.

Through subgroup analysis, we found better treatment effect with lower BMI and age. This result may be attributable to the fact that young people are more receptive to new treatments and more likely to be of lower weight than older people [5]. Likewise, young people often experience interpersonal problems, and there is strong evidence that IPT has a meaningful effect on the treatment of interpersonal problems in young people. At the same time, in the absence of interpersonal problems, the patient will actively participate in the treatment with better results [18]. This indicates that, to achieve optimal curative effect in the process of treating EDs, we should pay attention to the interpersonal problems of the patient.

While the meta-regression revealed that only $\mathrm{CBT}$ showed a dose-response relationship trend, these results should be treated with caution due to the limited number of studies available for analysis. If future research confirms a dose-response relationship in CBT-and if a dose-response relationship is discovered in IPTthen the frequency of sessions can be appropriately increased in clinical practice to obtain improved therapeutic effects. In fact, both IPT and CBT have been shown to alleviate patients' harmful eating habits and improved their mental condition, although without directly affecting weight. Therefore, another potential benefit of therapy is to assist bariatric surgery patients [35].

The follow-up effect analysis showed the same effects for IPT and CBT. However, there were no precise and consistent time points for follow-up, such as 2 months, 7 months, and 15 months. As such, the analysis can provide only a rough follow-up statistical result. The ideal duration of treatment is not known. For this reason, more precise time frames should be collected in future research to conduct a thorough follow-up analysis.

\section{Limitations}

This study is subject to a few limitations. First, the number of studies included was only ten. Therefore, some conclusions offered by this meta-analysis require additional research to confirm. Second, five studies in this meta-analysis were considered as having a high risk of bias because of their random sequence generation. Third, to identify potential factors that could cause interference, more detailed patient information is needed, such as session, gender, and the number of patients that dropped out of treatment [24]. Given the lack of this type of data, we could not perform subgroup analysis; yet, these factors could have an impact on the results. In future research, more comprehensive information collection should be conducted to obtain more data for a reliable meta-analysis.

\section{Conclusion}


Although further studies are needed to verify the treatment effects, our findings appear to lend support to the comparable effectiveness of IPT versus CBT at treating EDs. This meta-analysis also showed that people with lower BMls and young people with EDs experienced better treatment effects with IPT, which indicates that IPT may be preferable in these populations because eliminating interpersonal problems allows them to actively cooperate with treatment and achieve better results. Additionally, achieving an optimal number of treatment sessions can make a positive contribution to the therapeutic effect.

Both CBT and IPT directly target binge eating and related pathologies and are related to the highest shortterm and long-term binge eating withdrawal rates. However, several important areas of IPT treatment for EDs require further research. To better understand all of the problems that IPT can address, future research should continue to evaluate the effects of IPT on EDs, on excessive weight gain, and on other psychological problems. Furthermore, understanding how IPT achieves its therapeutic benefits can help improve the active therapeutic components in future treatment research, potentially promoting the further development of IPT [33]. Due to the low usage of IPT and patients' unfamiliarity with it, another important aspect of future research will be to promote IPT to assist clinicians in learning the technique and facilitate patient acceptance [22].

\section{Declarations}

Funding This work was supported by the Anhui Natural Science Foundation (1808085MH291), and the project of human social science of Anhui province (SK2016A047), and Grants for Scientific Research of BSKY (XJ201826) from Anhui Medical University.

Conflict of interest On behalf of all authors, the corresponding author states that there is no conflict of interest

Ethical approval This article does not contain any studies with human participants or animals performed by any of the authors.

Informed consent On behalf of all authors, the corresponding author states that informed consent was provided by all participants.

\section{References}

1. Agras WS, Telch CF, Arnow B, Eldredge K, Detzer MJ, Henderson J, Marnell M (1995) Does interpersonal therapy help patients with binge eating disorder who fail to respond to cognitive-behavioral therapy? J Consult Clin Psychol 63(3):356-360. https://doi.org/10.1037//0022-006x.63.3.356

2. Arcelus J, Whight D, Langham C, Baggott J, McGrain L, Meadows L, Meyer C (2009) A case series evaluation of a modified version of interpersonal psychotherapy (IPT) for the treatment of bulimic eating disorders: a pilot study. Eur Eat Disord Rev 17(4):260-268. https://doi.org/10.1002/erv.932

3. Berger SS, Elliott C, Ranzenhofer LM, Shomaker LB, Hannallah L, Field SE, Young JF et al (2014) Interpersonal problem areas and alexithymia in adolescent girls with loss of control eating. Compr 
Psychiatry 55(1):170-178. https://doi.org/10.1016/j.comppsych.2013.08.005

4. Berkman ND, Lohr KN, Bulik CM (2010) Outcomes of eating disorders: a systematic review of the literature. Int J Eat Disord 40(4):293-309. https://doi.org/10.1002/eat.20369

5. Bergh C, Brodin U, Lindberg G, Södersten P (2002) Randomized controlled trial of a treatment for anorexia and bulimia nervosa. Proc Natl Acad Sci U S A 99(14):9486-9491.

https://doi.org/10.1073/pnas.142284799

6. Bruijniks SJE, DeRubeis RJ, Lemmens LHJM, Peeters FPML, Cuijpers P, Huibers MJH (2021) The relation between therapy quality, therapy processes and outcomes and identifying for whom therapy quality matters in CBT and IPT for depression. Behav Res Ther 139(1):103815.

https://doi.org/10.1016/j.brat.2021.103815

7. Carter FA, Jordan J, Mcintosh V, Luty SE, Mckenzie JM, Frampton C et al (2011) The long-term efficacy of three psychotherapies for anorexia nervosa: a randomized, controlled trial. Int J Eat Disord 44(7):647-654. https://doi.org/10.1002/eat.20879

8. Chakraborty K, Basu D (2010) Management of anorexia and bulimia nervosa: An evidence-based review. India J Psychiat 52(2):174-186. https://doi.org/10.4103/0019-5545.64596

9. Chui W, Safer DL, Bryson SW, Agras WS, Wilson GT (2007) A comparison of ethnic groups in the treatment of bulimia nervosa. Eat Behav 8(4):485-491. https://doi.org/10.1016/j.eatbeh.2007.01.005

10. Constantino MJ, Arnow BA, Blasey C, Agras WS (2005) The association between patient characteristics and the therapeutic alliance in cognitive-behavioral and interpersonal therapy for bulimia nervosa.

Psychol Assess 73(2):203-211. https://doi.org/10.1037/0022-006X.73.2.203

11. Cuijpers P, Geraedts AS, Oppen PV, Andersson G, Markowitz JC, Straten AV (2011) Interpersonal psychotherapy for depression: a meta-analysis. Am J Psychiatry 168(6):581-592.

https://doi.org/10.1176/appi.ajp.2010.10101411

12. Czaja J, Hartmann AS, Rief W, Hilbert A (2011) Mealtime family interactions in home environments of children with loss of control eating. Appetite 56(3):587-593.

https://doi.org/10.1016/j.appet.2011.01.030

13. Fairburn CG, Bailey SS, Basden S, Doll HA, Jones R, Murphy R, O'Connor ME, Cooper Z (2015) A transdiagnostic comparison of enhanced cognitive behaviour therapy (CBT-E) and interpersonal psychotherapy in the treatment of eating disorders. Behav Res Ther 70:64-71.

https://doi.org/10.1016/j.brat.2015.04.010

14. Fairburn CG, Harrison PJ (2003) Eating disorders. Lancet 361(9355), 407. https://doi.org/10.1016/S0140-6736(03)12378-1

15. Fairburn CG, Jones R, Peveler RC, Hope RA, O'Connor M (1993) Psychotherapy and bulimia nervosa. Longer-term effects of interpersonal psychotherapy, behavior therapy, and cognitive behavior therapy. Arch Gen Psychiatry 50(6):419-428. https://doi.org/10.1001/archpsyc.1993.01820180009001

16. Fairburn CG, Harrison PJ (2003) Eating disorders. Lancet (361): 407-410

17. Foa EB, Kozak MJ (1986) Emotional processing of fear: exposure to corrective information. Psychol Bull 99(1):20-35. https://doi.org/10.1037/0033-2909.99.1.20 
18. Filia K, Eastwood O, Herniman S, Badcock P (2021) Facilitating improvements in young people's social relationships to prevent or treat depression: A review of empirically supported interventions. Transl Psychiatry 11(1):305. https://doi.org/10.1038/s41398-021-01406-7

19. Hilbert A, Bishop ME, Stein RI, Tanofsky KM, Swenson AK, Welch RR, Wilfley DE (2012) Long-term efficacy of psychological treatments for binge eating disorder. Br J Psychiatry 200(3):232-237. https://doi.org/10.1192/bjp.bp.110.089664

20. Iacovino JM, Gredysa DM, Altman M, Wilfley DE (2012) Psychological treatments for binge eating disorder. Curr Psychiatry Rep 14(4):432-446. https://doi.org/10.1007/s11920-012-0277-8

21. Jakobsen JC, Hansen JL, Simonsen E, Gluud C (2011) The effect of interpersonal psychotherapy and other psychodynamic therapies versus 'treatment as usual' in patients with major depressive disorder. PLoS One 6(4):e19044. https://doi.org/10.1371/journal.pone.0019044

22. Karam AM, Fitzsimmons CEE, Tanofsky KM, Wilfley DE (2019) Interpersonal Psychotherapy and the Treatment of Eating Disorders. Psychiatr Clin North Am 42(2):205-218. https://doi.org/10.1016/j.psc.2019.01.003

23. Koskina A, Campbell IC, Schmidt U (2013) Exposure therapy in eating disorders revisited. Neurosci Biobehav R 37(2):193-208. https://doi.org/10.1016/j.neubiorev.2012.11.010

24. Linardon J, Fairburn CG, Fitzsimmons CEE, Wilfley DE, Brennan L (2017) The empirical status of the third-wave behaviour therapies for the treatment of eating disorders: A systematic review. Clin Psychol Rev 58:125-140. https://doi.org/10.1016/j.cpr.2017.10.005

25. Shomaker LB, Tanofsky KM, Matherne CE, Mehari RD, Olsen CH, Marwitz SE et al (2017) A randomized, comparative pilot trial of family-based interpersonal psychotherapy for reducing psychosocial symptoms, disordered-eating, and excess weight gain in at-risk preadolescents with loss-of-controleating. Int J Eat Disord 50(9):1084-1094. https://doi.org/10.1002/eat.22741

26. Muran JC (1991) A reformulation of the abc model in cognitive psychotherapies: implications for assessment and treatment. Clin Psychol Rev 11(4):399-418. https://doi.org/10.1016/02727358(91)90115-B

27. Méndez J, Sánchez H, Garber J, Espada JP, Orgilés M (2021) Psychological Treatments for Depression in Adolescents: More Than Three Decades Later. Int J Environ Res Public Health 18(9):4600. https://doi.org/10.3390/ijerph18094600

28. Miniati M, Callari A, Maglio A, Calugi S (2018) Interpersonal psychotherapy for eating disorders: current perspectives. Psychol Res Behav Manag 11:353-369. https://doi.org/10.2147/PRBM.S120584

29. Markowitz JC (1993) Psychotherapy of the postdysthymic patient. World Psychiaty 2(2):157-163

30. Murray SB, Griffiths S, Mond JM (2016) Evolving eating disorder psychopathology: Conceptualising muscularity-oriented disordered eating. Br J Psychiatry 208:414-415. https://doi.org/10.1192/bjp.bp.115.168427

31. McIntosh VVW, Jordan J, Carter FA, Luty SE, McKenzie JM, Bulik CM, Frampton CMA, Joyce PR (2005) Three psychotherapies for anorexia nervosa: a randomized, controlled trial. Am J Psychiatry 162(4):741-747. https://doi.org/10.1176/appi.ajp.162.4.741 
32. Reilly EE, Anderson LM, Gorrell S, Schaumberg K, Anderson DA (2017) Expanding exposure-based interventions for eating disorders. Int J Eat Disord 50(10):1137-1141.

https://doi.org/10.1002/eat.22761

33. Tanofsky KM, Shomaker LB, Wilfley DE, Young JF, Sbrocco T, Stephens M et al (2014) Targeted prevention of excess weight gain and eating disorders in high-risk adolescent girls: a randomized controlled trial. Am J Clin Nutr 100(4):1010-1018. https://doi.org/10.3945/ajcn.114.092536

34. Tasca GA, Balfour L, Presniak MD, Bissada H (2012) Outcomes of specific interpersonal problems for binge eating disorder: comparing group psychodynamic interpersonal psychotherapy and group cognitive behavioral therapy. Int J Group Psychother 62(2):197-218.

https://doi.org/10.1521/ijgp.2012.62.2.197

35. Vaidya V (2006) Cognitive behavior therapy of binge eating disorder. Adv Psychosom Med 27:86-93. https://doi.org/10.1159/000090966

36. Virginia VWM, Dip C, Jennifer J, Dip C, Janet DC, Dip C et al (2016) Assessing the distinctiveness of psychotherapies and examining change over treatment for anorexia nervosa with cognitive-behavior therapy, interpersonal psychotherapy, and specialist supportive clinical management. Int J Eat Disorder 49(10):958-962. https://doi.org/10.1002/eat.22555

37. Wade TD, Bergin JL, Martin NG, Gillespie NA, Fairburn CG (2006) A transdiagnostic approach to understanding eating disorders. J Nerv Ment Dis 194:510-517.

https://doi.org/10.1097/01.nmd.0000225067.42191.b0

38. Wilfley DE, Welch RR, Stein RI, Spurrell EB, Cohen LR, Saelens BE et al (2002) A randomized comparison of group cognitive-behavioral therapy and group interpersonal psychotherapy for the treatment of overweight individuals with binge-eating disorder. Arch Gen Psychiatry 59(8):713-721. https://doi.org/10.1001/archpsyc.59.8.713

39. Wilfley DE, Vannucci A, White EK (2010) Early intervention of eating- and weight-related problems. J Clin Psychol Med Settings 17(4):285-300. https://doi.org/10.1007/s10880-010-9209-0

40. Wilson GT, Wilfley DE, Agras WS, Bryson SW (2010) Psychological treatments of binge eating disorder. Arch Gen Psychiatry 67(1):94-101. https://doi.org/10.1001/archgenpsychiatry.2009.170

\section{Figures}




\section{PRISMA 2009 Flow Diagram}

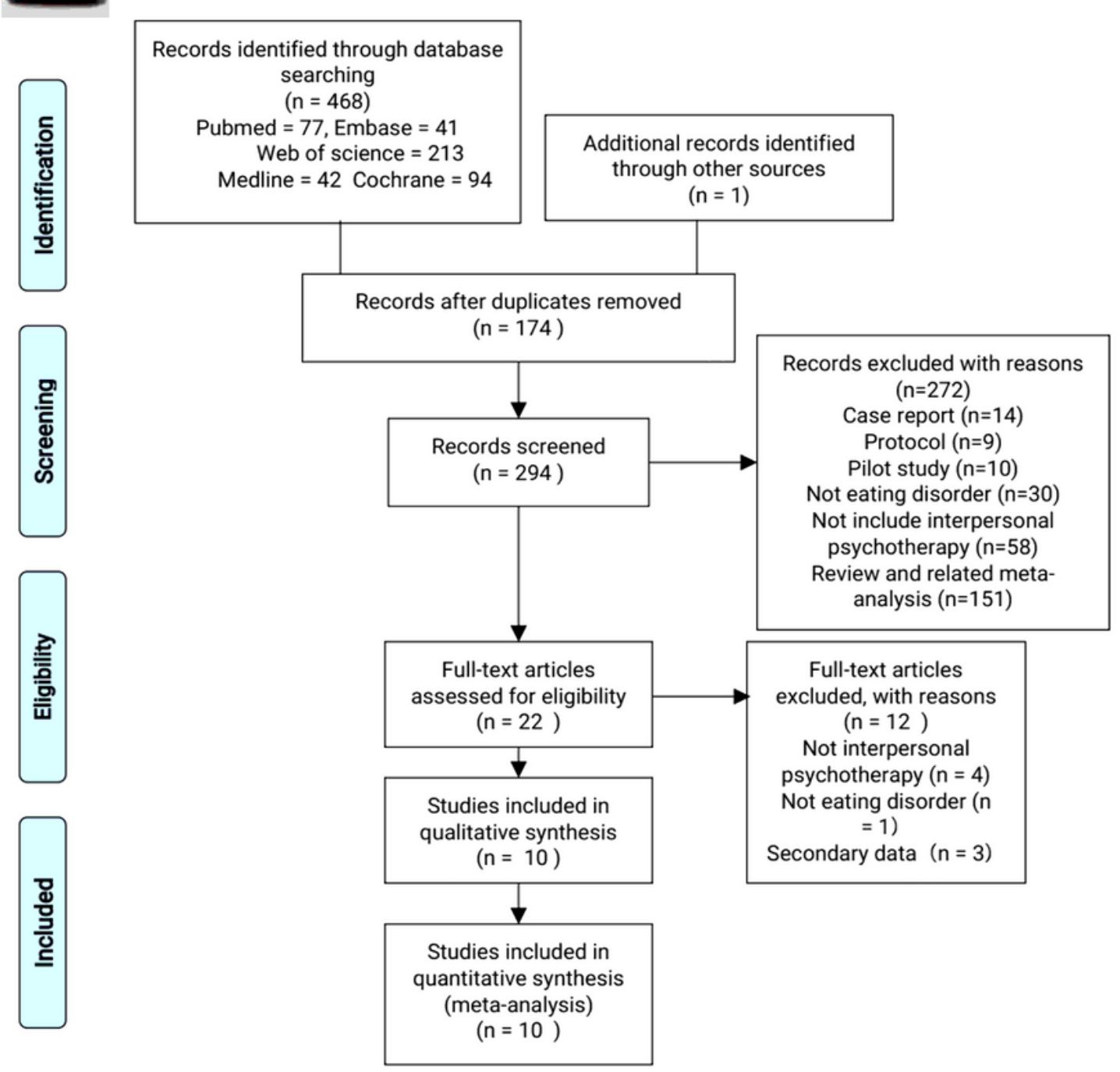

From: Moher D, Liberati A, Tetzlaff J, Altman DG, The PRISMA Group (2009). Preferred Reporting Aems for Systematic Reviews and MetaAnalyses: The PRISMA Statement. PLoS Med 6(7): e1000097. doi:10.1371/journal.pmed1000097

For more information, visit www.prisma-statement.org.

\section{Figure 1}

PRISMA flow chart of study selection. 




B

\begin{tabular}{|c|c|c|c|c|c|c|c|}
\hline & 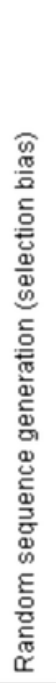 & 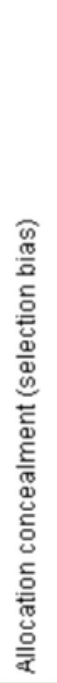 & 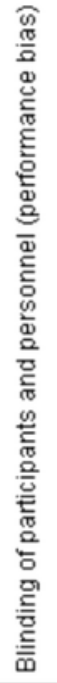 & 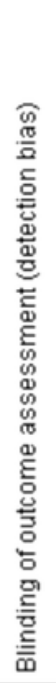 &  & 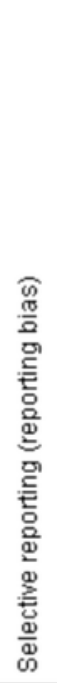 & 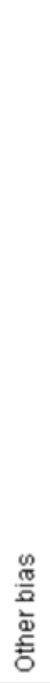 \\
\hline Agras 1995 & $\theta$ & $?$ & $\odot$ & $\odot$ & + & + & $?$ \\
\hline Carter 2011 & $\odot$ & ? & $\odot$ & $\odot$ & $\odot$ & $\odot$ & $\odot$ \\
\hline chui 2007 & $\odot$ & $\odot$ & $\odot$ & $\odot$ & $\odot$ & $\odot$ & $\theta$ \\
\hline Fairburn 1993 & $\odot$ & ? & $\odot$ & $\odot$ & $\odot$ & $\odot$ & $?$ \\
\hline Fairburn 2015 & ○ & $\odot$ & $\odot$ & $\odot$ & $\odot$ & $\odot$ & $\odot$ \\
\hline hilbert 2012 & $\odot$ & $?$ & $\odot$ & $\odot$ & $\odot$ & $\odot$ & $?$ \\
\hline Mcintosh 2005 & $\odot$ & ? & $\odot$ & $\odot$ & $\odot$ & $\odot$ & $\odot$ \\
\hline Tasca 2012 & $?$ & ? & $\odot$ & $\odot$ & $\odot$ & 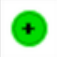 & 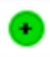 \\
\hline Wilfley 2002 & $\odot$ & $?$ & $\odot$ & $\odot$ & $\odot$ & $\odot$ & 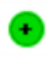 \\
\hline wilson 2010 & $\odot$ & $\odot$ & $\odot$ & $\odot$ & $\odot$ & $\odot$ & $\odot$ \\
\hline
\end{tabular}

\section{Figure 2}

Quality assessment of RCTs. (A) Risk of bias graph: review authors' judgments about each risk of bias item presented as percentages across included studies. (B) Risk of bias summary: review authors' judgments about each risk of bias item for each included study. 


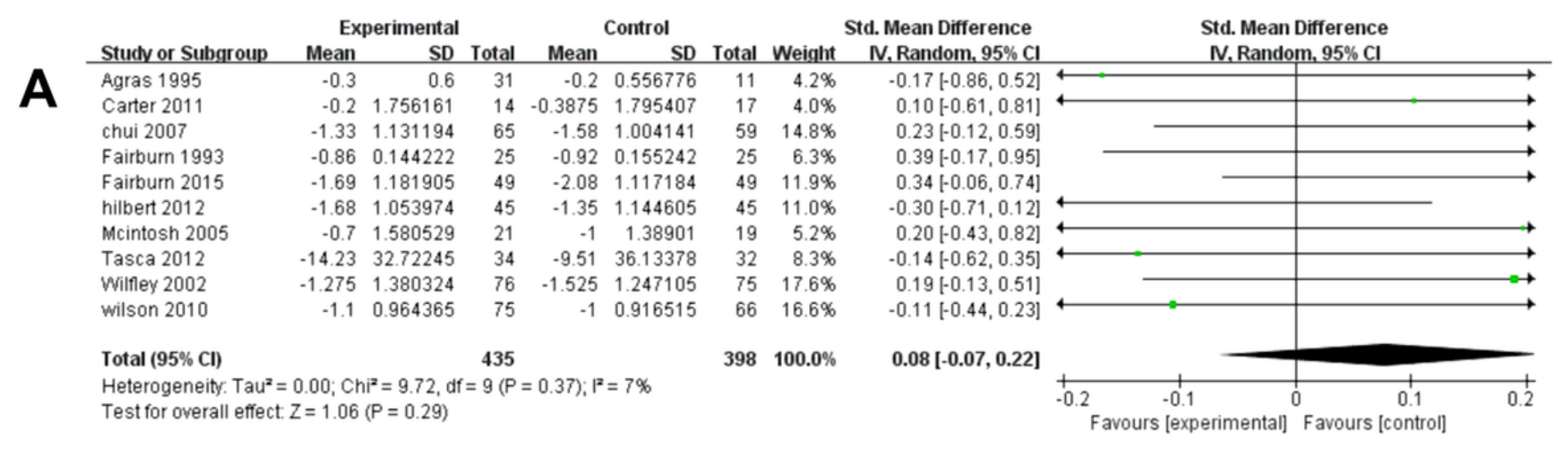

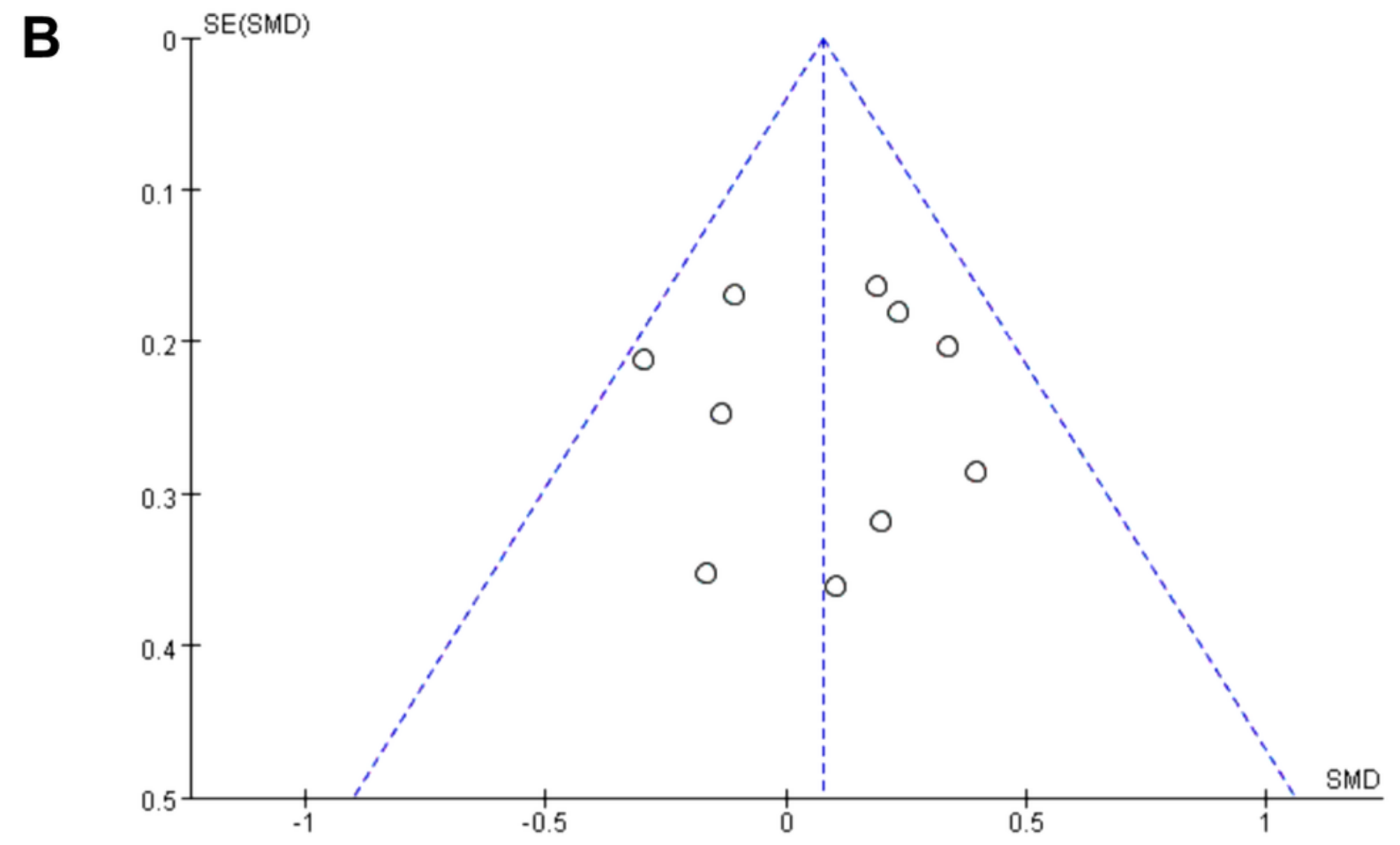

\section{Figure 3}

Primary outcome analysis. (A) Meta-analysis of the effect of IPT vs CBT on ED. (B) Funnel plot. 

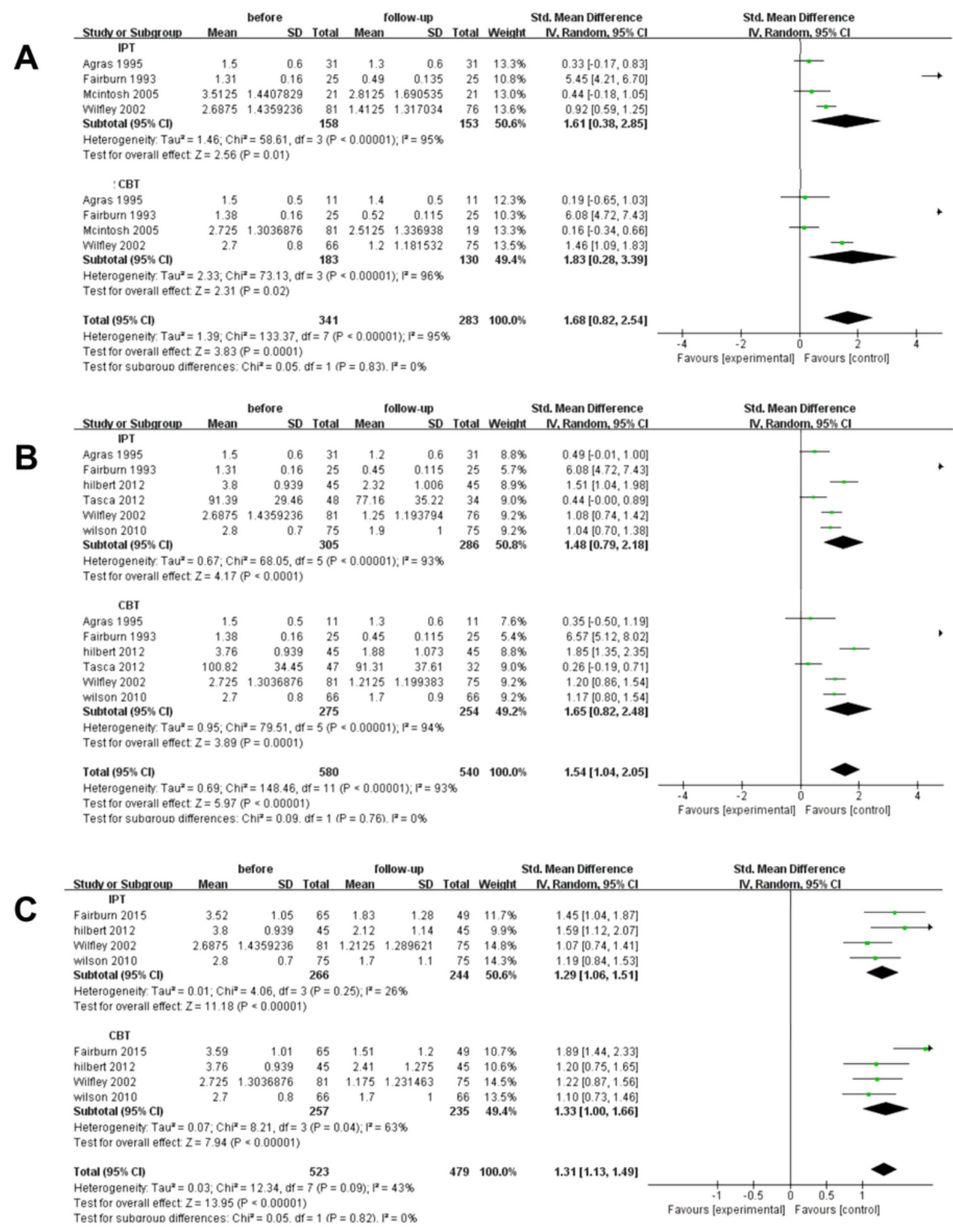

\section{Figure 4}

The follow-up effect of IPT vs CBT. (A) Follow-up time is less than six months. (B) Follow-up time is greater than six months and less than one year. (C) Follow-up time is greater than one year. 




\section{Figure 5}

Secondary outcome analysis. 

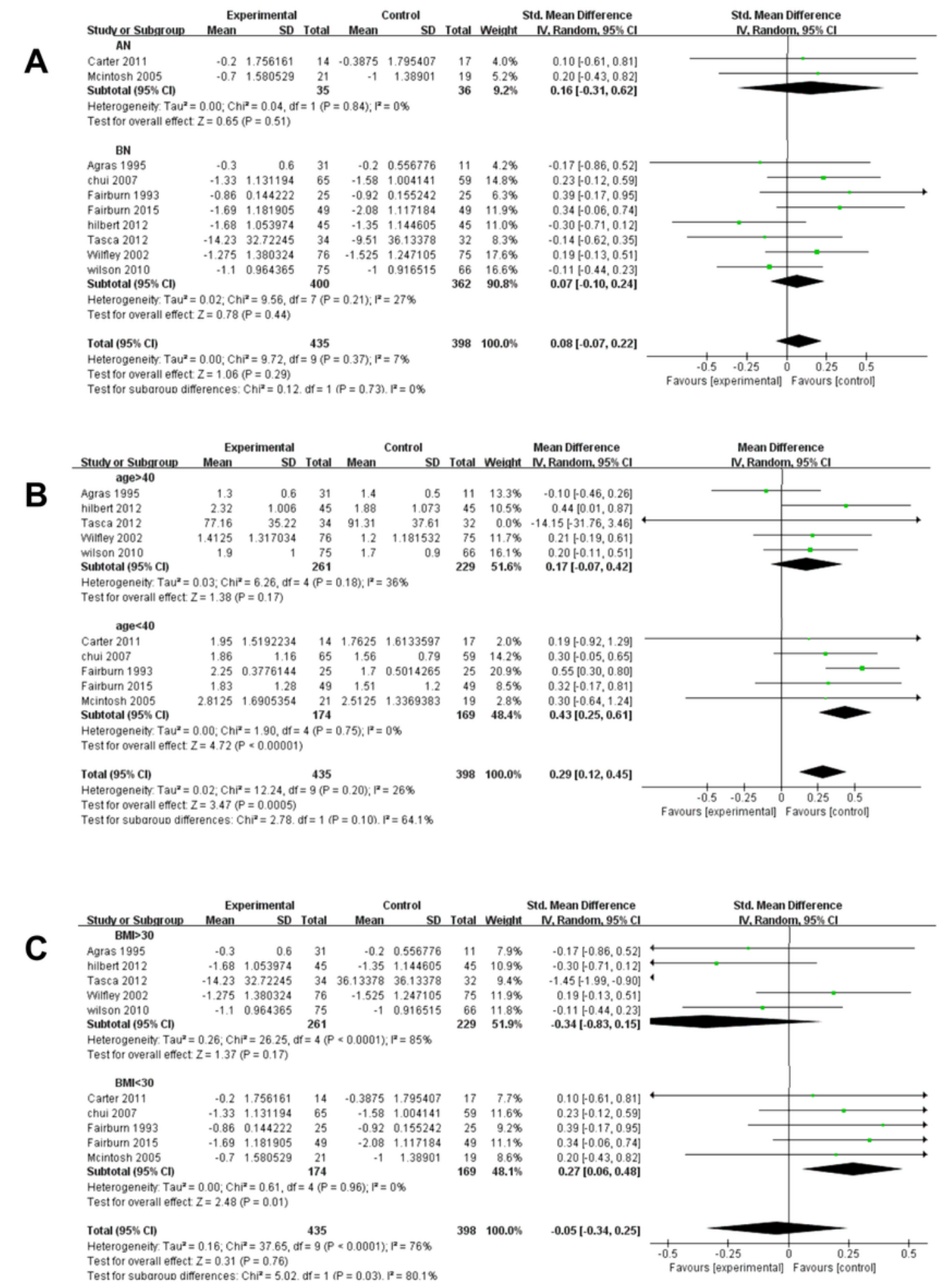

\section{Figure 6}

Subgroup analysis. (A) Types of eating disorders: AN vs BN. (B) The patient is older than 40 vs younger than 40. (C) The patient's BMl is greater than 30 vs less than 30. 
A

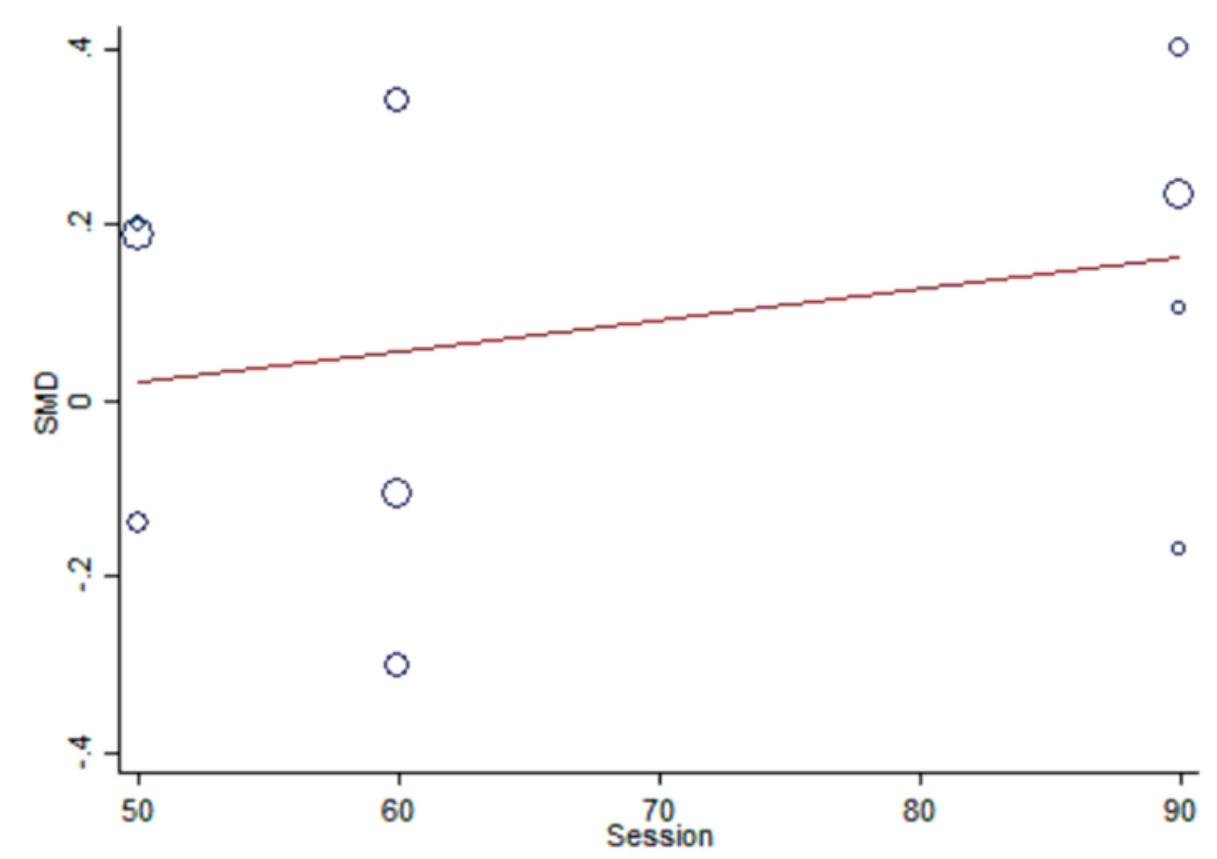

B

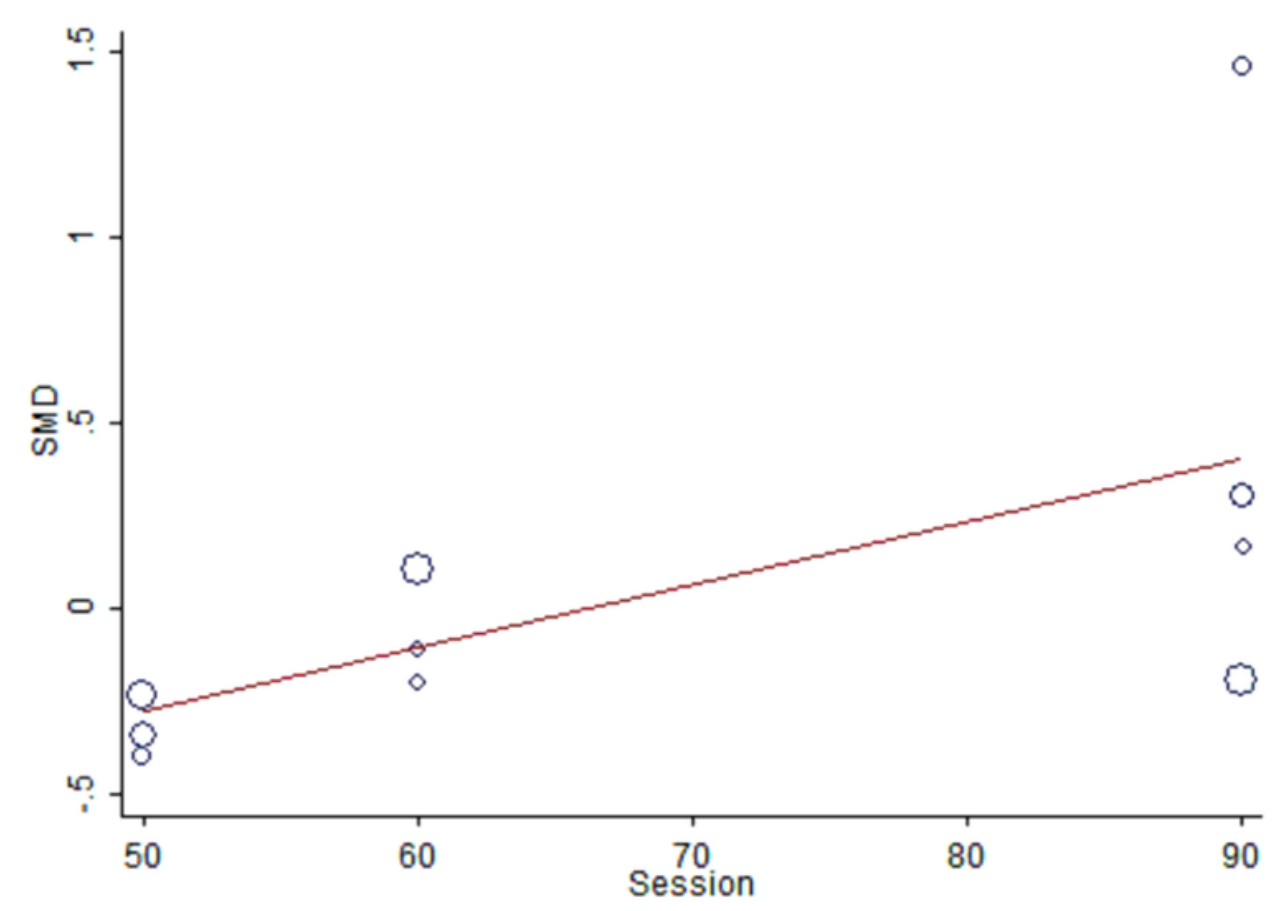

\section{Figure 7}

Meta-regression analysis of treatment session. (A) IPT session. (B) CBT session. 